\title{
Betel Quid Chewing in the Mid-Atlantic United States: Any Consequence?
}

\author{
Sneha Shah, DMD, Thaddeus S Boucree MD, DDS* and Eric I Chang, MD, FACS
}

Newark Beth Israel Medical Center, USA

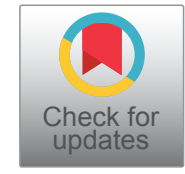

*Corresponding author: Thaddeus S Boucree 201 Lyons Ave, Newark, NJ 07112, USA

\begin{abstract}
According to the NYU Center for the Study of Asian American Health, the New York City Metropolitan area is home to the largest concentration of South Asians in the United States [1]. The chewing of betel quid related products is common to these immigrants from countries including India, Pakistan, Bangladesh, Sri Lanka, Nepal, Bhutan, and the Maldives among others [1]. Betel quid and its constituent areca nut are known risk factors for many oral and esophageal cancers [2]. However, the lack of awareness regarding adverse effects of the areca nut among its users, limited understanding of its cultural role among healthcare providers, and lack of global policy for control of the substance has resulted in what has been termed a global public health emergency [2]. Within a six-month period from October 2017 to March 2018, three cases of oral squamous cell carcinoma were diagnosed at St. Joseph's University Medical Center in Paterson, $\mathrm{NJ}$ and treated using wide local excision and reconstructive flap surgery. All three patients were South Asian immigrants, and in each case, the patient admitted to a history of ten or more years of betel quid chewing. Considering these cases, the purpose of this presentation is to report on the incidence of oral squamous cell carcinoma in the greater New York and New Jersey area associated with betel quid use the purpose of this paper is to report on the rising incidence of squamous cell carcinoma.
\end{abstract}

\section{Introduction}

During a period from October 2017 to March 2018, three separate patients presented to the OMFS service at St. Joseph's University Medical Center via clinic referrals and emergency room visits whose biopsy results returned positive for oral squamous cell carcinoma secondary to betel quid use. This high concentration of betel quid users in Paterson, NJ during a relatively short period of time piqued our interest in understanding the biology, mechanisms, and epidemiology of betel quid use particularly within the Greater New York/New Jersey area. Although the popular- ity of betel quid and areca nut use worldwide is comparable to that of tobacco, alcohol, and caffeine, a March 2018 publication by the International Society for the Prevention of Tobacco Induced Diseases notes that no global policy exists for the control of these known human carcinogens [2]. The purpose of this article is to review the basics of betel quid composition and patterns of its use; to investigate the potential rise in incidence of betel nut related oral cancers in the United States; and to provide an overview of the three cases which have been our lens into the subject.

\section{Background}

The areca nut, which is commonly but incorrectly referred to as the "betel nut," is popularly consumed recreationally and as a snack throughout South Asia in various forms such as mawa, paan, gutka, paan masala, and khaini [3]. Generally, these consist of slivers or powdered form of areca nut, slaked lime, and areca catechu [3]. These basic ingredients are sometimes also combined with tobacco and various flavor-enhancing spices [3]. Unlike chewing tobacco, paan is not considered taboo within South Asian cultural tradition including Indian and Bangladeshi culture. Many people begin using paan or gutka as teenagers and will chew and spit it out or swallow it multiple times throughout the day [4]. Traditional Indian medicine known as Ayurveda cites several medical uses of the areca nut, including as an anthelmintic, appetite stimulant, flatus reliever, dentifrice, diuretic, and laxative [4]. It is popularly used as a palate cleanser and breath freshener [4]. Chronic consumers enjoy its euphoric effects and use it to combat fatigue, attain satiation, stimulate salivation, and relieve toothaches [4] (Table 1) (Figure 1).

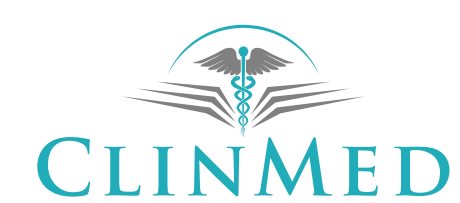

INTERNATIONAL LIBRARY 
Table 1: Source: These are some popular areca nut and betel quid products, their common forms, and countries of use [2].

\begin{tabular}{|c|c|c|}
\hline & Countries of use $[5,6]$ & Products definitions (forms and type of tobacco and added ingredients) \\
\hline $\begin{array}{l}\text { Areca } \\
\text { nut husk } \\
\text { without } \\
\text { tobacco [7] }\end{array}$ & Mainland China & $\begin{array}{l}\text { Custom-made or handmade product that consists of the husk of the } \\
\text { Piper betle plant mixed with other ingredients (eg. Dried grapes) }\end{array}$ \\
\hline $\begin{array}{l}\text { Betel } \\
\text { quid with } \\
\text { tobacco } \\
\text { (eg, paan) } \\
{[5,8]}\end{array}$ & $\begin{array}{l}\text { Bangladesh, Cambodia, China, } \\
\text { Indonesia, India, Federated States of } \\
\text { Micornesia, Laos, Malaysia, Maldives, } \\
\text { Myanmar, Papau New Guinea, Nepal, } \\
\text { Pakistan, Palau, Singapore, SriLanka, } \\
\text { Taiwan, Thailand, United Arab } \\
\text { Emirates, UK, Vietnam }\end{array}$ & $\begin{array}{l}\text { Commercial or vendor-prepared packaged product, or handmade or } \\
\text { home prepared by the user with tobacco; contains areca nut, slaked } \\
\text { lime, betel leaf, and often catechu; other ingredients are added that } \\
\text { differ regionally such as cardamon, saffron, cloves, aniseed, turmeric, } \\
\text { mustard, sweeteners, rosewater, aniseed, mint, or other spices }\end{array}$ \\
\hline $\begin{array}{l}\text { Betel } \\
\text { quid with } \\
\text { tobacco } \\
{[5,3]}\end{array}$ & $\begin{array}{l}\text { Taiwan, Papau New Guinea, Solomon } \\
\text { Islands }\end{array}$ & $\begin{array}{l}\text { Custom-made or handmade product that is a combination of betel leaf, } \\
\text { areca nut, or fruit of a pepper plant (piper betle), and powered lime; } \\
\text { other ingredients and spices can be added to enhance flavouring; often } \\
\text { prepared by warpping the areca nut, and part of the betel pepper vine } \\
\text { with or without the other ingredients in a Piper betle leaf }\end{array}$ \\
\hline $\begin{array}{l}\text { Gutkha or } \\
\text { gutka }[5,8]\end{array}$ & $\begin{array}{l}\text { Bangladesh, India, Myanmar, Nepal, } \\
\text { Pakistan, Sri Lanka }\end{array}$ & $\begin{array}{l}\text { Commercially manufactured and packaged form of tobacco product } \\
\text { containing crushed areca nut and catechu that are mixed together with } \\
\text { various flavourings and sometimes sweeteners }\end{array}$ \\
\hline $\begin{array}{l}\text { Khaini, } \\
\text { Khoini }[5,8]\end{array}$ & Bangladesh, Bhutan, India, Nepal & $\begin{array}{l}\text { Commercially prepared or custom-made product containing powederd } \\
\text { tobacco mixed with slaked lime paste and sometimes areca nut }\end{array}$ \\
\hline Manipuri [5] & Uttar Pradesh, India & $\begin{array}{l}\text { Handmade or custom-made product containing tobacco mixed, areca } \\
\text { nut, camphor and cloves }\end{array}$ \\
\hline $\begin{array}{l}\text { Mawa, } \\
\text { Kharra [5] }\end{array}$ & Gujarat, Maharashtra, India & $\begin{array}{l}\text { Handmade or custom-made product or locally produced and wrapped } \\
\text { in cellophane, containing small pieces of areca nut }(95 \%) \text { that are } \\
\text { mixed with tobacco flakes and slaked lime, then the mixture is rubbed } \\
\text { together to combine }\end{array}$ \\
\hline $\begin{array}{l}\text { Naswar } \\
\text { (niswar) } \\
{[5,10]}\end{array}$ & Afganistan, India, Pakistan & $\begin{array}{l}\text { Custom-made form of tobacco that is a combination of ingredients } \\
\text { including slaked lime, ash, oil, sometimes flavourings (most commonly } \\
\text { menthol and cardamom), and a colouring agent (such as indigo) }\end{array}$ \\
\hline $\begin{array}{l}\text { Zaarda or } \\
\text { zarda }[5,10]\end{array}$ & $\begin{array}{l}\text { Bangladesh, Bhutan, India, Myanmar, } \\
\text { Nepal, UK, Yemen }\end{array}$ & $\begin{array}{l}\text { Commercially produced product containing tobacco, lime, spices, } \\
\text { vegetable dyes, and sometimes areca nut; processed with broken } \\
\text { tobacco leaves boiled with lime and spices; the mixture is dried and } \\
\text { coloured with vegetables dyes, then sometimes mixed with areca nut }\end{array}$ \\
\hline
\end{tabular}
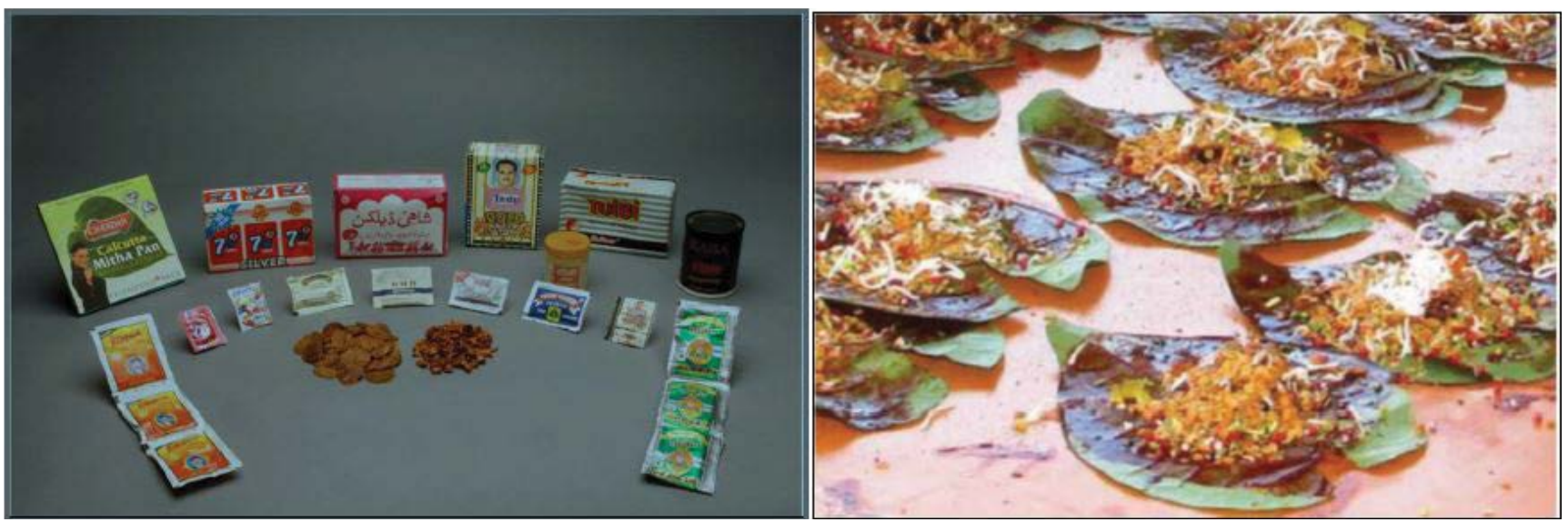

Figure 1: a) Source: Blank, et al. Packaged areca nut products which can be purchased in [5] b) Source: Aziz (2010). Freshly prepared paan, made to order at a roadside stand in New Jersey [4].

\section{Biochemistry and carcinogenesis}

Carcinogenesis in the setting of betel quid and areca nut use has no clear model comparable to that of smokeless tobacco use [2]. However, a few mechanisms have been proposed, many of which involve the compound arecoline [2]. The model presented here is de- scribed in a 2004 publication from the German Cancer Research Center in Heidelberg, Germany.

According to this model, betel quid carcinogenesis is a result of multiple biochemical processes resulting in miscoding DNA adducts and reactive oxygen species [9]. Arecoline is the primary alkaloid present in the are- 


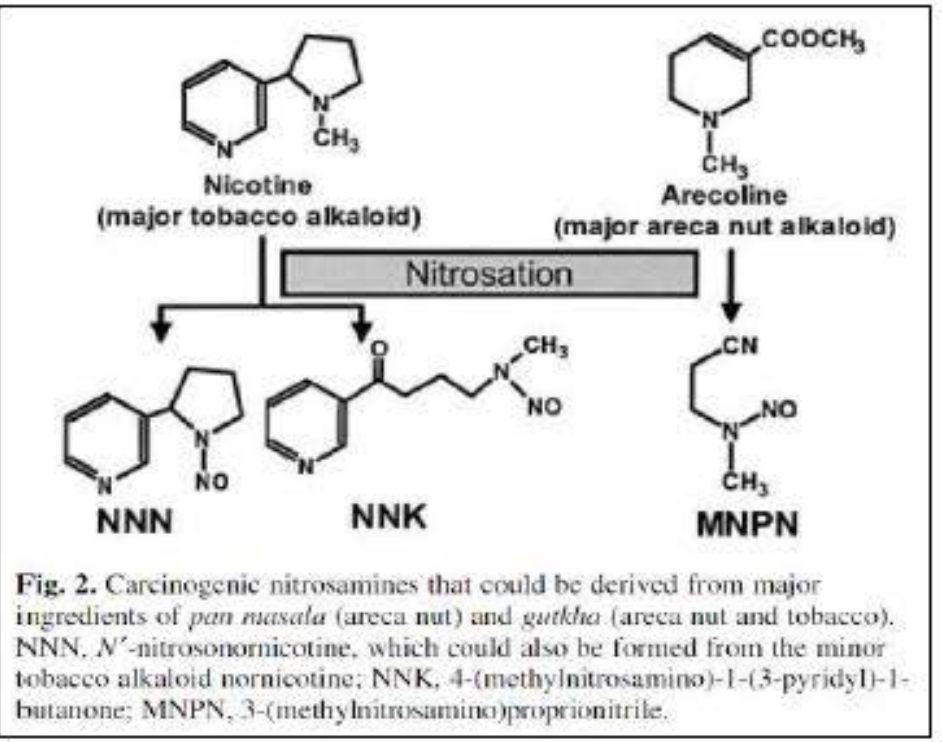

Figure 2a. Source: Nair (2004). ${ }^{6}$

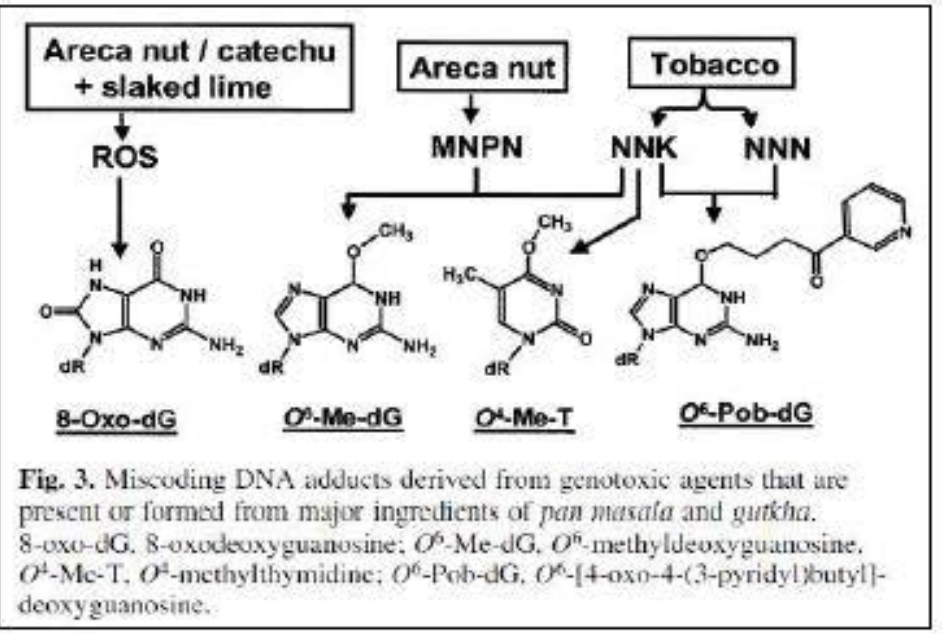

Figure 2b. Source: Nair (2004). ${ }^{6}$

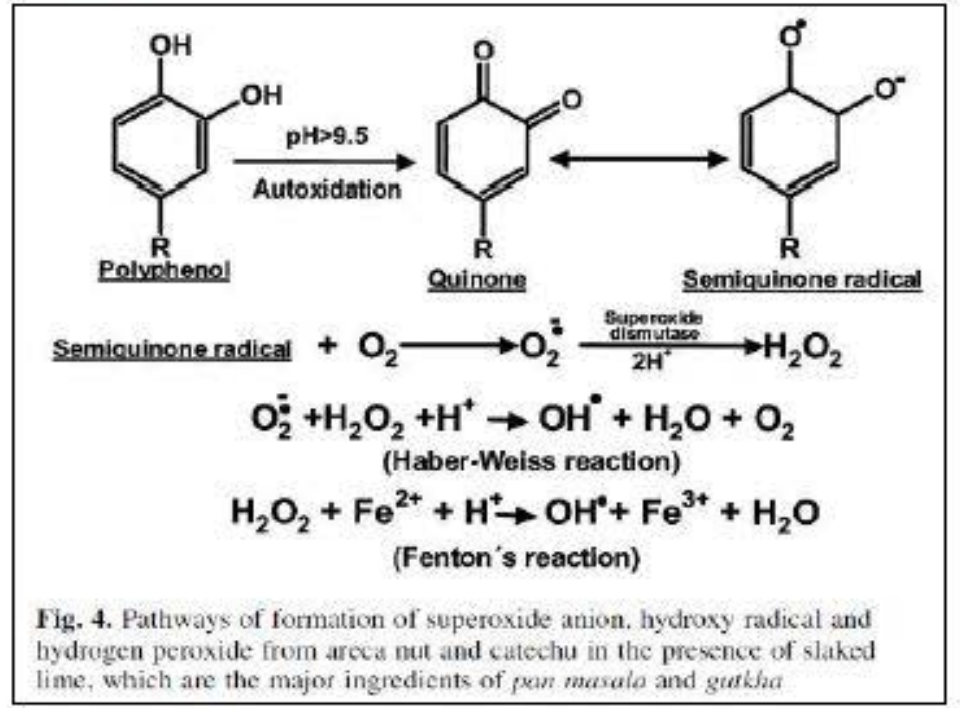

\section{Figure 2c. Source: Nair (2004) ${ }^{6}$}

Figure 2: a) Source: Nair a) Carcinogenic nitrosamines that could be derived from major ingredients of Pan masala (areca nut) and gutkha (areca nut and tobacco); b) Miscoding DNA adducts derived from genotoxic agents that are present or formed from major ingredients of pan masala and gutkha, C) Pathways of formation of superoxide anion, hydroxyl radical and hydrogen peroxide from areca nut catechu in the presence of slaked lime, which are the major ingredients of pan masala and gutkhs [9]. 
ca nut comprising $1 \%$ of its dry weight [9]. By a process called nitrosation (Figure 2a), nicotine from tobacco and arecoline from areca nut are transformed into nitrosamines [9]. These genotoxic agents are found in the saliva of betel quid consumers after metabolic activation as opposed to in the products themselves [9].

The nitrosation process is enhanced in the presence of nitric oxide and nitrate formed during deposition of dental plaque [9]. Therefore, betel nut chewing in the setting of poor oral hygiene poses an even greater risk for development of oral squamous cell carcinoma. As a testament to this, a case-control study of risk factors for oral squamous cell carcinoma done in Chidambaram, South India which was published in the European Journal of Cancer Prevention in 2007 shows a positive association between poor oral hygiene and poor dentition with the risk of oral squamous cell carcinoma [10].

When slaked lime, which consists of caustic calcium hydroxide, is added into the preparation, the alkaline environment promotes formation of reactive oxygen species (Figure 2b and Figure 2c) (Table 2) [9]. In 2004, areca nut chewing was classified as carcinogenic to humans by the International Agency for Research on Cancer (IARC).

\section{Oral submucous fibrosis}

In addition to alkaloids, betel quid also contains flavonoids and copper [4]. The combination of these is implicated in the development of a pre-malignant condition specific to areca nut chewing, which is known as oral submucous fibrosis or OSF [4]. This is a disease of collagen metabolism resulting in fibrosis and decreased

Table 2: Source: Major carcinogenic and genotoxic agents in pan masala and gutkha [6].

\begin{tabular}{|l|l|l|}
\hline Products & Ingredients & Genotoxic agents/carcinogens \\
\hline Gutkha & Tobacco & NNN, NNK \\
\hline & Areca nut & arecoline, MNPN \\
\hline & Areca nut + lime & ROS \\
\hline Pan masala & Catechu + lime & ROS \\
\hline & Areca nut & arecoline, MNPN \\
\hline & Areca nut + lime & ROS \\
\hline & Catechu + lime & ROS \\
\hline
\end{tabular}

NNN, N'-nitrosonornicotine; NNK, 4-(methylnitrosamine)-1-(3-pyridyle)-1-butanone; MNPN, 3 (methylnitrosamine) propionitrile; ROS, reactive oxygen species, $\mathrm{O}^{-}, \mathrm{H}_{2} \mathrm{O}_{2}, \mathrm{OH}$.

aFor structures and pathways see Figures 2 and Figure 3.

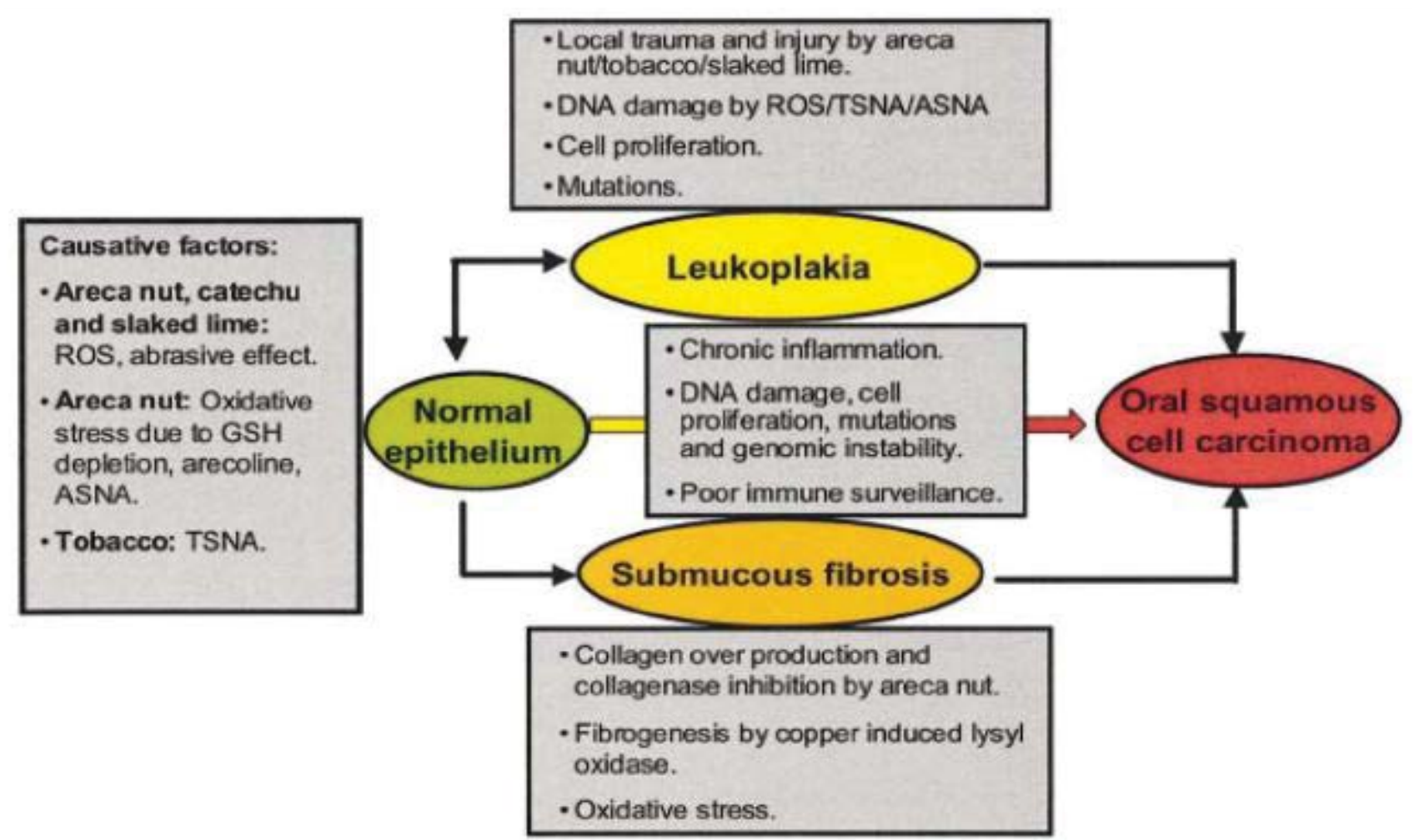

Figure 3: Source: Nair [9]. Summary of the proposed mechanism of oral premalignant lesions and carcinogenesis due to use of areca products. 
collagen breakdown [4]. As S R Aziz delineates in his article published in JADA in 2010, alkaloids stimulate fibroblasts to produce collagen; flavonoids inhibit collagenase; and copper, which is yet another constituent of areca nut products, stimulates the lysyl oxidase enzyme involved in the final cross-linking of collagen fibers [4]. Clinically, the earliest sign of OSF is mouth soreness with burning when eating spicy foods (Table 3). OSF can often be cured by quitting betel nut use before trismus develops [4]. Once trismus has developed, the disease is irreversible and may require a combination of physical therapy and surgical intervention to treat [4].

The generated nitrates and reactive oxygen species can cause potentially malignant oral lesions (PMOL); or chronic inflammation of normal epithelium can rapidly progress to oral squamous cell carcinoma (Figure 3 ).

\section{Betel nut and oral cancer}

Nearly every betel quid and tobacco chewing-related oral malignancy is preceded by a clinically distinct PMOL such as OSF, leukoplakia, erythroplakia, or some combination of these at the site of cancer development [9]. In particular, a dose-dependent relationship has been suggested between frequency of areca nut use and the relative risk of OSF [9]. Conversely, roughly $2-12 \%$ of PMOLs have been reported to undergo malignant transformation [9]. Additionally, the likelihood of malignant transformation may increase when areca nut use is combined with tobacco and alcohol use [10]. The aforementioned study from Chidambaram, South India reports significantly higher rates of malignant transformation among the illiterate population, farmers, and those who maintain a non-vegetarian diet [10]. Thus, there is a well-established relationship between areca nut use with or without additional high-risk habits and development of oral squamous cell carcinoma $[6,10]$.

\section{Statistics}

According to data from the World Cancer Research Fund, cancer of the lip and oral cavity ranks $16^{\text {th }}$ in incidence among both men and women worldwide with 354,864 new cases reported in 2018 [7]. The greatest concentration of these cases is found in Southern Asia in countries like India, Bangladesh, and Sri Lanka and the Pacific Islands. A fact sheet published by the International Agency for Research on Cancer (IARC) indicates that cancers of the lip and oral cavity rank second in incidence among all reported cancer diagnoses in 2018 in both Bangladesh and India [8,12]. The reported 119,992 new cases in India and 13,401 new cases in Bangladesh

Table 3: Source: Clinical features of oral submucous fibrosis* [11].

\begin{tabular}{|c|c|}
\hline & Clinical feature \\
\hline \multicolumn{2}{|l|}{ Early } \\
\hline & Balnching of mucosa \\
\hline & Intolerance of spicy foods \\
\hline & Petechiae \\
\hline & Oral ulceration \\
\hline & Leathery mucosa \\
\hline & Taster disturbance \\
\hline \multicolumn{2}{|l|}{ Late } \\
\hline & Fibrous bands \\
\hline & Trismus \\
\hline 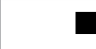 & Flattening of palate \\
\hline & "Hockey stick" uvula \\
\hline $\mathbf{E}$ & Reduction in tongue mobility \\
\hline 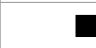 & Xerostomia \\
\hline
\end{tabular}
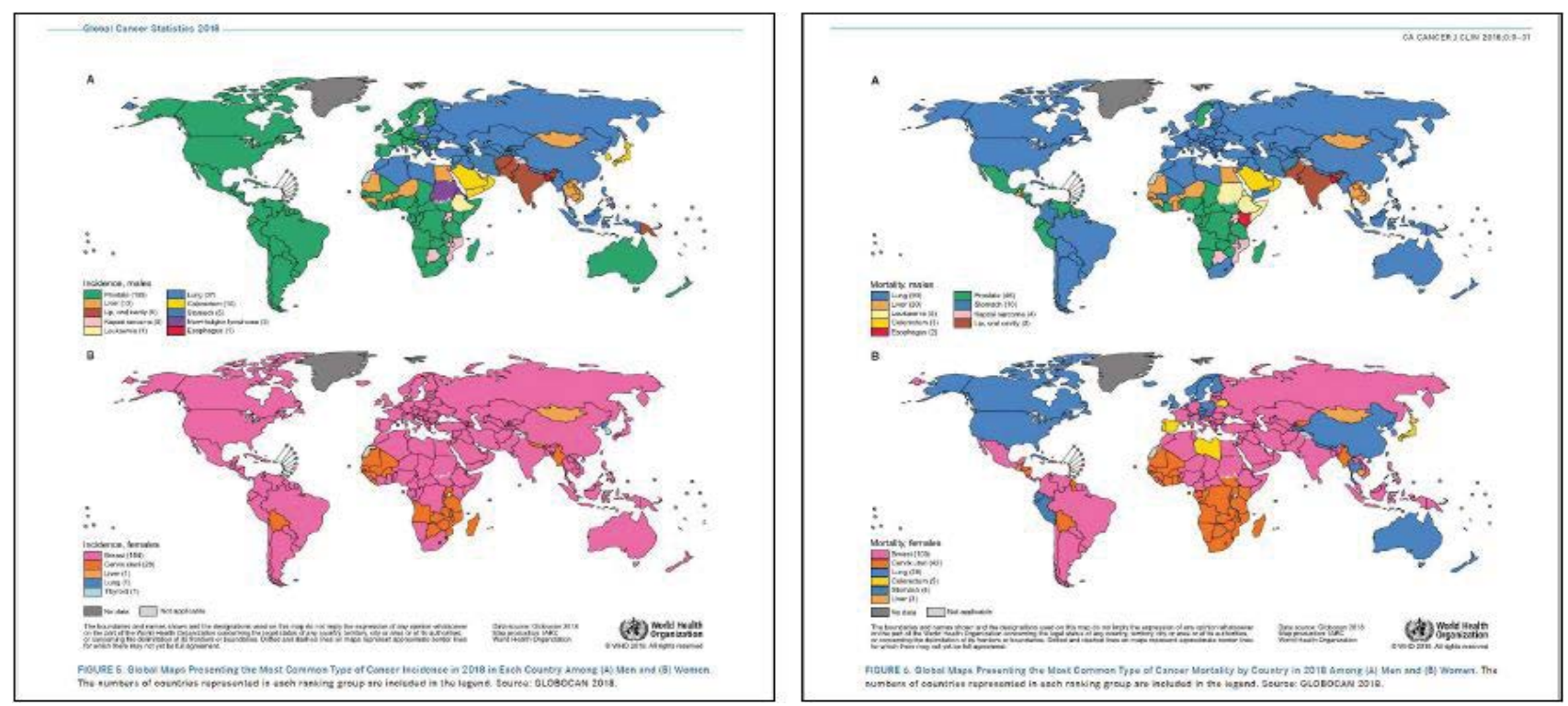

Figure 4: Source: Bray, et al. [12]. Global maps presenting the most common type of cancer incidence in 2018 in each country a) Men and b) Women. The numbers of countries represented in each ranking group are included in the legend. Source: GLOBOCAN 2018. 
in 2018 far surpass the United States, which reports 24,229 new cases of cancers of the oral cavity and lip in 2018 with an overall rank of $20^{\text {th }}$ in incidence as compared to other cancers $[8,12]$.

These maps produced by the IARC in 2018 offer a visual summary of these statistics. The top map in Figure 4 a shows the Indian subcontinent and Papa New Guinea colored to indicate that cancers of the lip and oral cavity represent the most common type of cancer incidence in these regions in 2018 among men. The top map in Figure $4 \mathrm{~b}$ shows the Indian subcontinent colored to indicate that these same cancers are also the leading cause of cancer mortality in males in this region.

\section{Discussion}

As immigration from these countries to the United States continues to rise, there may be a corresponding rise in incidence of oral cancer. According to data from the US Department of Homeland Security, India ranks among the top 6 countries of origin for individuals who have been granted legal permanent resident status in 2017 and during the first quarter of fiscal year 2018 [13].

A report prepared by the Migration Policy Institute in July 2014 states that nearly half of all Bangladeshi immigrants arrived in the United States in or after 2000, implying a trending increase in immigration [14]. Furthermore, New York City and the surrounding metropolitan areas were found to host the greatest concentration of Bangladeshi immigrant communities (Figure 5). This growth in Indian and Bangladeshi immigration to the greater New York City area may be evidenced on a small scale by the increase in number of betel quid related cancer diagnoses during the period from October 2017 to March 2018 at St. Joseph's University Medical Center in Paterson, NJ.

This intersection of immigration and incidence of oral cancer has previously been noted in British and Canadian studies which show that immigrants tend to continue betel quid chewing habits in their new homes $[3,4]$. As a result of this, South Asian communities in the United Kingdom have an incidence of oral cancer comparable to that observed in the Indian subcontinent [4]. The roadside paan shops found in suburban New Jersey's South Asian neighborhoods are evidence of a similar trend in the United States. A community-based pilot study done in New York City in 2006 revealed that Indian-Gujarati and Bangladeshi immigrants to the United States continue to use paan and gutka despite being generally aware of their negative health effects [15]. Thus, a protocol for prevention, identification, and

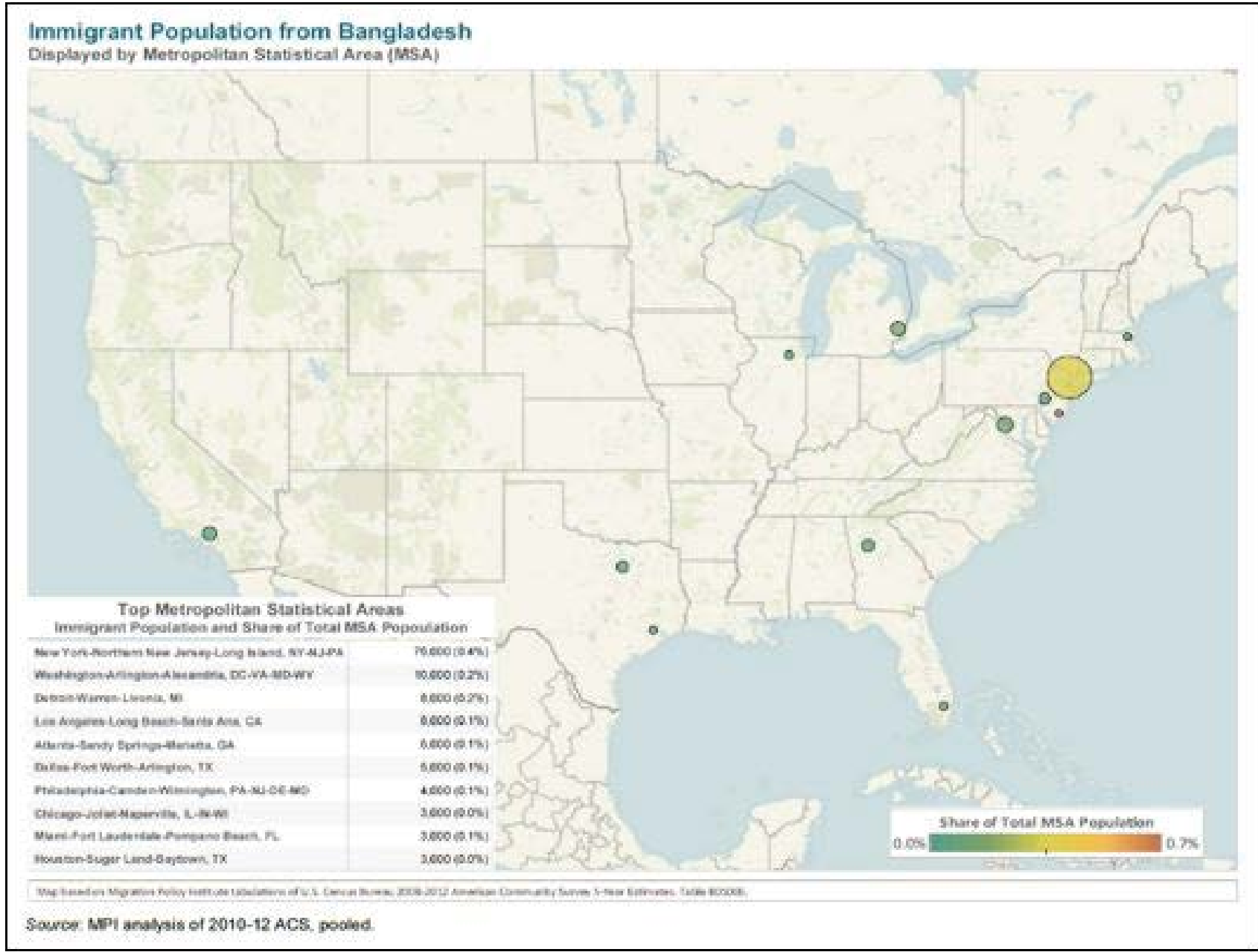

Figure 5: Source: MPI analysis of 2010-12 ACS, pooled [14]. 
treatment of oral cancer for this particular demographic is in order [16].

Considering the relatively low incidence of cancers of the lip and oral cavity observed in the United States as a whole, the presentation of three unrelated patients in Paterson, NJ with a diagnosis of oral squamous cell carcinoma within a short four-month span is of interest. The first of these patients was an Indian-Gujarati male who reported a previous history of oral squamous cell carcinoma for which he had undergone surgery and radiation therapy in Gujarat, India five years prior. The second patient was an Indian-Gujarati male who presented with a chief complaint of a persistent ulcer of his right buccal mucosa which had been unsuccessfully treated with topical ointments by his primary care physician. The third patient was a Bengali female who presented with a chief complaint of trismus and ulceration of the left buccal mucosa. In each case, patients admitted to greater than 20 years of betel nut use.

\section{Case Series}

\section{Case 1}

In late October 2017, a 54-year-old Indian-Gujarati male presented to SJUMC Paterson's oral and maxillofacial surgery clinic with a chief complaint of loose teeth and persistent pain in the anterior mandible for one month. A history was obtained with help from a translator, as the patient could only effectively communicate in Gujarati. He reported a previous diagnosis of oral squamous cell carcinoma of the anterior tongue and floor of the mouth which was treated with left hemiglossectomy, radical neck dissection of the left side, and 60 Gy radiation to the left neck in Gujarat, India in 2012. He admitted to several years of betel quid chewing and social alcohol consumption in India prior to his first diagnosis of OSCC but had quit both habits since his surgery. Within one year of treatment, he immigrated to the United States with his family and was lost to follow up. His mandibular incisors were recently extracted by his dentist in the US, as they were loose and painful; and he was eventually referred to the OMFS clinic at SJUMC for evaluation of persistent pain and abnormal tissue growth in the region.

An incisional biopsy was done under local anesthesia in the OMFS clinic, which returned positive for squamous cell carcinoma of the anterior mandible with extension into the skin of the chin and extension into the floor of the mouth. The lesion was clinically staged T4bNOMO. No palpable lymph nodes were detected, and a chest X-ray was obtained which did not reveal any additional lesions. After his case was presented to the multidisciplinary cancer consortium at SJUMC, a decision was made to proceed with surgical resection.

On December 11, 2017, the patient was taken to the operating room where tracheostomy and PEG tube were placed by the general surgery team. Direct laryngoscopy revealed that the vocal cords and epiglottis were free of disease on visual inspection. Partial glossectomy, mandibulectomy, and right selective neck dissection at levels I-III were completed. A fibula free flap was harvested from the right leg and used to reconstruct the mandibular defect. Microvascular anastomosis was achieved between the recipient superior thyroid artery and the donor peroneal artery using 8-0 silk sutures and between the recipient external jugular vein and donor peroneal vein using a venous coupler. Doppler sonography was used to confirm perfusion of the flap in the operating room and every hour in the immediate post-operative period. The final pathologic diagnosis was determined to be pT4aNOMX. This was later modified to pT4aNOM0, as no distant metastases were found on a full body PET scan. After a 35-day hospital stay, the patient was discharged home with adequate homecare arrangements made, and a monthly outpatient follow-up regimen was instituted.

The hematology and oncology team at SJUMC determined that our patient would benefit from chemotherapy, as one positive margin and a residual mass were noted at the surgical site. Cetuximab therapy was begun via peripheral IV every two weeks. Due to severe skin and nail changes, hypermetabolic uptake in the region of the reconstruction plate, and disease progression, a decision was made to switch to carboplatin and paclitaxel every three weeks. Considering his previous radiation therapy in 2012, the radiation oncologist deemed him not to be a candidate for radiation treatment for his present illness (Figure 6).

\section{Case 2}

In late December of 2017, a 56-year-old Indian-Gujarati male presented to SJUMC Paterson's emergency department complaining of a painful infection in his right cheek that was producing pus and blood. He reported pain in his right cheek for one month, secondary to accidental cheek biting. His dentist prescribed triamcinolone topical ointment, which exacerbated his symptoms, and antibiotics, which provided some relief. He admitted to a history of daily betel quid use which he began over thirty years ago.

An incisional biopsy of the right and left buccal mucosa was done under local anesthesia in the OMFS clinic, which returned positive for squamous cell carcinoma of the right buccal mucosa, moderately to well differentiated. The lesion was clinically staged T2NOMX, no palpable lymph nodes were detected, and a chest X-ray was obtained which did not reveal any additional lesions. After his case was presented to the multidisciplinary cancer consortium at SJUMC, a decision was made to proceed with surgical resection.

On $14^{\text {th }}$ February 2018 , the patient was taken to the operating room where a PEG tube was placed by the 

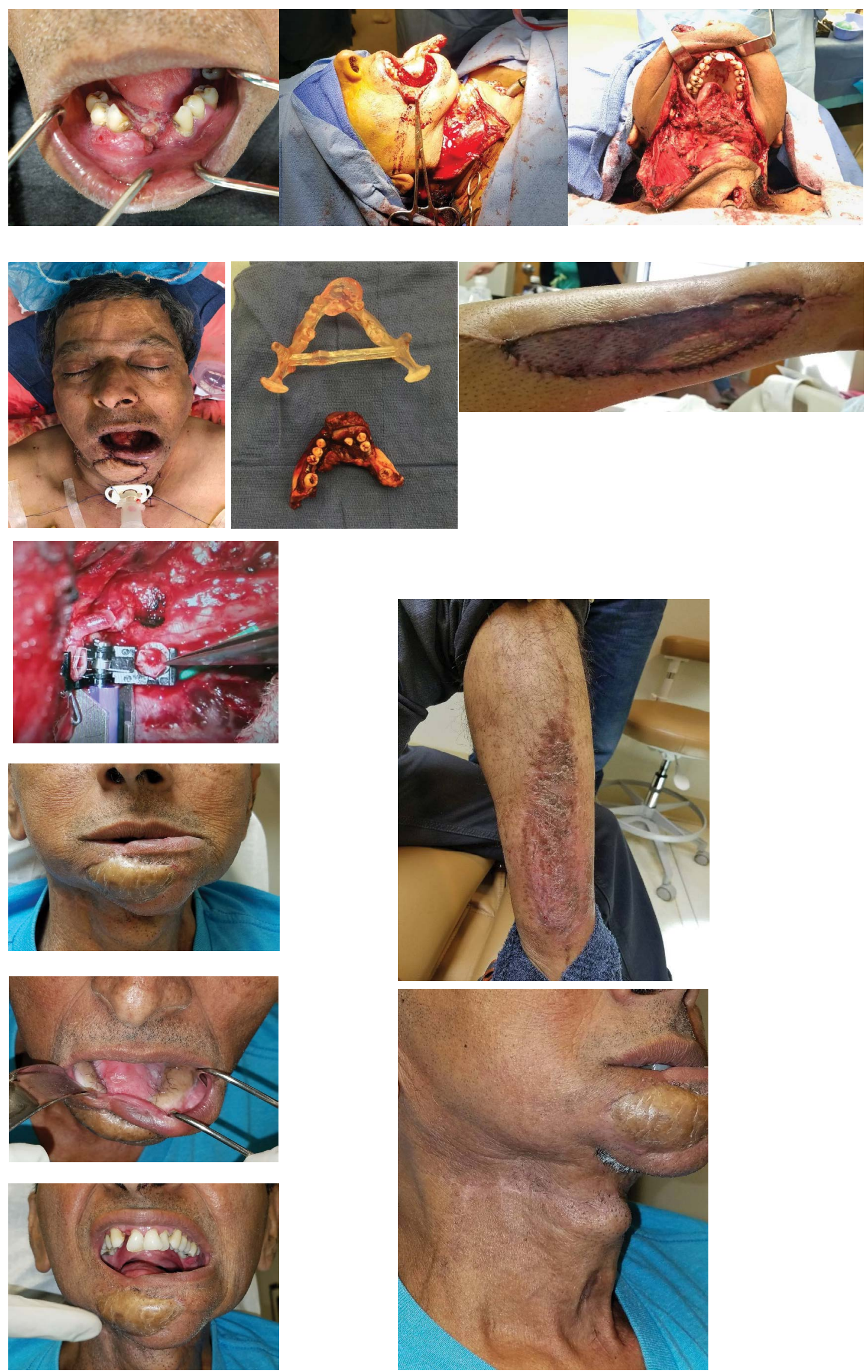

Figure 6: (a) Case 1, preoperative clinical image of floor of mouth and anterior mandible; (6b) Case 1, intra-operative photo of partial glossectomy, mandibulectomy, right selective neck dissection at levels I-III; (6c) Case 1, intra-operative axial view status postpartial glossectomy, mandibulectomy, right selective neck dissection at levels I-III; (6d) Case 1, immediate postoperative image following primary closure of incisions; (6e) Case 1, resected mandible including tumor; (6f) Case 1, postoperative image of free fibula harvest site status post split-thickness skin graft reconstruction; (6g) Case 1, microvascular venous anastomosis using venous coupler; (6h-I) Case 1 , several weeks post-operative follow-up. 



Figure 7: (a) Case 2, preoperative clinical photo of right buccal lesion; (b) Case 2, outline of surgical incisions intraoperatively; (c) Case 2, intra-operative image of right midfacial defect following tumor resection; (d) Case 2, resected tumor with wide margins, measuring $7.5 \mathrm{~cm}$ in widest diameter; (e) Case 2, right selective neck dissection at levels I-III; (f) Case 2, right anterior lateral thigh harvest site; (g) Case 2, approximation of anterior lateral thigh microvascular free flap to right midfacial defect for reconstruction; (h) Case 2, microvascular arterial anastomosis using 8-0 nylon sutures. Notice venous anastomosis below with venous couplers; (i) Case 2, purulence expressed from infected flap approximately 3 weeks postoperatively; (j) Case 2, following debridement of infected flap tissue and release of sutures from superomedial portion of flap; (k) Case 2, flap healing well several weeks postoperatively following resolution of infection. 
General Surgery team. Direct laryngoscopy revealed that the vocal cords and epiglottis were free of disease on visual inspection. Wide excision of the right buccal mucosa squamous cell carcinoma, right partial maxillectomy, right marginal mandibulectomy, right selective neck dissection at levels I-III were completed. An anterolateral thigh free flap was harvested from the right leg and used to reconstruct the right buccal defect. Microvascular anastomosis was achieved between the recipient superior thyroid artery and donor lateral circumflex artery and between the recipient facial vein and donor vena comitante. Doppler sonography was used to confirm perfusion of the flap in the operating room and every hour in the immediate post-operative period. The final pathologic diagnosis was determined to be $\mathrm{PT} 2 \mathrm{~N} 1 \mathrm{MX}$, as one positive lymph node was found.

The post-operative course was complicated by infection and dehiscence of the flap approximately three weeks after his surgery. He was taken back to the operating room for debridement and closure of the wound dehiscence. The post-operative course was uneventful thereafter. He was discharged home and a monthly follow-up regimen was instituted.
The hematology and oncology team at SJUMC determined that no chemotherapeutic intervention was indicated. However, he underwent radiation therapy after consultation with the radiation oncologist, due to lymphovascular and perineural invasion associated with the single positive lymph node (Figure 7).

\section{Case 3}

In January of 2018, a 39-year-old Bangladeshi female presented to SJUMC Paterson's Oral \& Maxillofacial Surgery clinic complaining of trismus and a painful pimple on her inner left cheek which she first noticed about 2.5 months prior. A history was obtained with help from a translator, as the patient could only effectively communicate in Bengali. She admitted to greater than 20 years of betel quid chewing in a form identified by her son as "gua."

An incisional biopsy was done under local anesthesia in the OMFS clinic, which returned positive for invasive and in-situ squamous cell carcinoma of the left buccal mucosa, moderately to poorly differentiated. The lesion was clinically staged T2NOMO, no palpable lymph nodes were detected, and a chest X-ray was obtained which
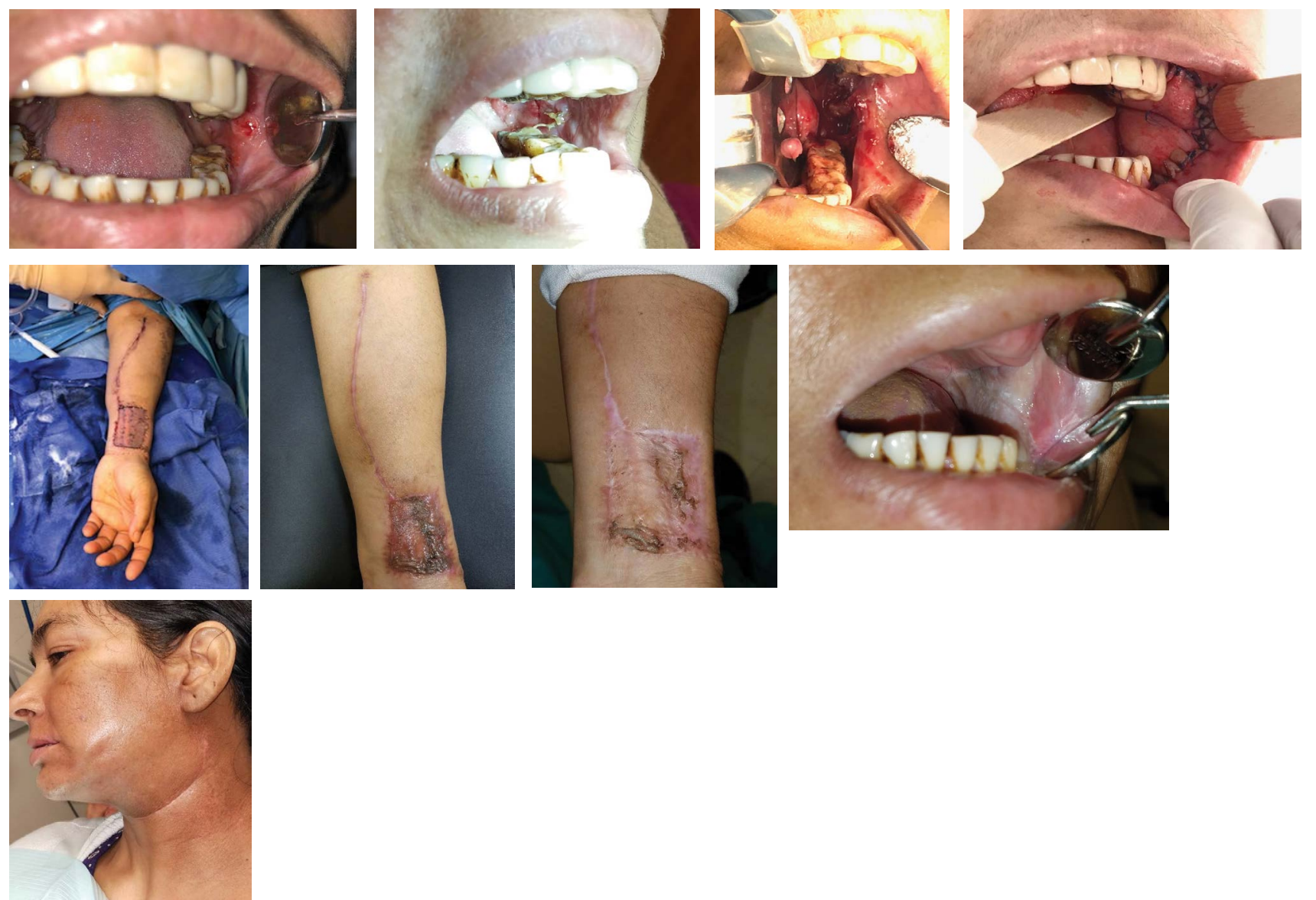

Figure 8: (a) Case 3, preoperative clinical image of left buccal mucosal lesion; (b) Case 3, clinical image of left buccal mucosal lesion one week after initial biopsy; (c) Case 3, intraoperative image of left buccal defect following wide local excision of tumor; (d) Case 3, postoperative image of left buccal reconstruction with radial forearm free flap; (e) Case 3, intra-operative image of left radial forearm free flap following closure of harvest site; (f-g) Case 3, healing left radial forearm harvest site several weeks postoperatively; (h) Case 3, healed left buccal mucosal radial forearm free flap, several weeks postoperatively; (i) Case 3, healed left neck incision several weeks status post left selective neck dissection at levels I-III and initiation of radiation therapy. 
ruled out metastasis to the lungs. After his case was presented to the multidisciplinary cancer consortium at SJUMC, a decision was made to proceed with surgical resection.

On March 8, 2018, the patient was taken to the operating room where wide local excision of the left buccal mucosa squamous cell carcinoma, left partial hemimaxillectomy, left marginal mandibulectomy, andleft selective neck dissection at levels I-III were completed. $A$ radial forearm free flap was harvested from the left forearm for reconstruction of the left buccal defect.

Microvascular anastomosis was achieved between the recipient facial artery and donor radial artery and between the recipient external jugular vein and donor radial vein. Doppler sonography was used to confirm perfusion of the flap in the operating room and every hour in the immediate post-operative period. The final pathologic diagnosis was determined to be pT2NOMO, as no positive lymph nodes were found.

The hematology and oncology team at SJUMC determined that no chemotherapeutic intervention was indicated. However, she underwent radiation therapy after consultation with Radiation Oncology due to the depth of invasion (Figure 8).

\section{Conclusion}

Betel quid use with and without tobacco are proven risk factors for oral pre-cancers. It has been implicated in the development of pre-malignant and malignant lesions of the oral cavity. Nonetheless, betel quid and various forms of areca nut consumption remain a common practice within the South/Southeast Asian community around the world. Cultural betel quid use migrates to the Greater New York/New Jersey area along with immigrants, particularly from Bangladesh and India. As evidenced by these three patients, Paterson, NJ is home to several such immigrants. This case series and the literature reviewed in this article illustrate the need for greater attention to this global public health emergency. There is a need for patient education regarding the effects of betel nut chewing in all its various forms; and healthcare professionals must share their clinical experiences to optimize care and management of these patients going forward.

\section{References}

1. NYU Center for the Study of Asian American Health. In The South Asian Community in the United States \& New York City.

2. Parascandola $M$, Mehrtash $H$, Ndumele $A$, Duncan $K$ (2018) Prioritizing a global research and policy agenda for Betel Quid (BQ) and Areca Nut (AN). Tobacco Induced Diseases 16.

3. Auluck A, Hislop G, Poh C, Zhang L, Rosin MP (2009) Areca nut and betel quid chewing among South Asian immigrants to Western countries and its implications for oral cancer screening. Rural and Remote Health 9: 1118.
4. Aziz SR (2010) Coming to America: Betel nut and oral submucous fibrosis. Journal of the American Dental Association 141: 423-428.

5. Blank M, Deshpande L, Balster RL (2008) Availability and Characteristics of Betel Products in the U.S. Journal of Psychoactive Drugs 40: 309-313.

6. Jacob BJ, Straif K, Thomas G, Ramadas K, Mathew B, et al. (2004) Betel quid without tobacco as a risk factor for oral precancers. Oral Oncology 40: 697-704.

7. (2018) World Cancer Research Fund International.

8. (2018) Cancer today.

9. Nair U, Bartsch H, Nair J (2004) Alert for an epidemic of oral cancer due to use of the betel quid substitutes gutkha and pan masala: A review of agents and causative mechanisms. Mutagenesis 19: 251-262.

10. Subapriya R, Thangavelu A, Mathavan B, Ramachandran CR, Nagini S (2007) Assessment of risk factors for oral squamous cell carcinoma in Chidambaram, Southern India: A case-control study. European Journal of Cancer Prevention 16: 251-256.

11. Trivedy CR, Craig G, Warnakulasuriya S (2002) The oral health consequences of chewing areca nut. Addict Biol 7: 115-125.

12. Bray F, Ferlay J, Soerjomataram I, Siegel RL, Torre LA, et al. (2018) Global cancer statistics 2018: GLOBOCAN estimates of incidence and mortality worldwide for 36 cancers in 185 countries. CA: A Cancer Journal for Clinicians 68: 394-424.

13. (2018) Legal Immigration and Adjustment of Status Report.

14. (2014) RAD Diaspora Profile: The Bangladeshi Diaspora in the United States. DC: Migration Policy Institute, Washington, 1-8.

15. Changrani J, Cruz G, Kerr R, Katz R, Gany FM (2006) Paan and Gutka Use in the United States. Journal of Immigrant \& Refugee Studies 4: 99-109.

16. Shield KD, Ferlay J, Jemal A, Sankaranarayanan R, Chaturvedi AK, et al. (2016) The global incidence of lip, oral cavity, and pharyngeal cancers by subsite in 2012. CA: A Cancer Journal for Clinicians 67: 51-64.

17. Johnson N, Franceschi S, Ferlay J, Ramadas K, Schmid S, et al. (2005) Tumors of the Oral Cavity and Oropharynx. In: Pathology and Genetics of Head and Neck Tumors. Blue Book Series, WHO Publications Center, NY, 168-175.

18. Kademani D, Tiwana PS (2016) Atlas of oral \& maxillofacial surgery. St. Louis: Elsevier Saunders. 